ГОРЛОВ Константин Николаевич - соискатель Института социально-политических исследований РАН; старший преподаватель кафедры управления и делового администрирования Мичуринского государственного аграрного университета; заместитель председателя Мичуринского городского Совета депутатов Тамбовской области (393764, Россия, Тамбовская обл., г. Мичуринск, ул. Красная, 973; gorlov@cit-tmb.ru)

ПЕНЬКОВ Владимир Федорович - доктор политических наук, профессор; профессор кафедры теории и истории государства и права Тамбовского государственного технического университета; председатель Общественной палаты Тамбовской области (392000, Россия, г. Тамбов, ул. Советская, 106; pvf68@mail.ru)

\title{
ФОРМИРОВАНИЕ ДОВЕРИЯ БИЗНЕСА И ВЛАСТИ В УСЛОВИЯХ ЦИФРОВИЗАЦИИ РОССИЙСКОЙ ЭКОНОМИКИ
}

\begin{abstract}
Аннотация. В статье рассматривается современное понимание сущности и видов доверия в контексте взаимоотношений бизнеса и власти. Авторы анализируют влияние цифровизации, экономических и социально-политических процессов на уровень доверия в Российской Федерации. Определено, что современные цифровые технологии (блокчейн, искусственный интеллект, большие данные, цифровые платформы) становятся как источниками социально-политических и экономических рисков, снижающих уровень доверия в отношениях, так и инструментами формирования нового доверия в системе взаимоотношений бизнеса и власти. Авторы предлагают ряд мер как со стороны власти, так и со стороны бизнеса, направленных на построение эффективного механизма формирования взаимных доверительных отношений, особо отмечая необходимость заключения нового общественного договора, отвечающего реалиям цифровой трансформации общества.
\end{abstract}

Ключевые слова: доверие, цифровое доверие, бизнес, власть, цифровая экономика, цифровые технологии, общественный договор

\section{Введение}

Среди поправок к Конституции РФ, принятых летом 2020 г. по итогам общероссийского голосования, есть правовая новелла, закрепляющая создание в стране условий для «взаимного доверия государства и общества» 1 . В феврале 2021 г. президент России В. Путин подписал указ, согласно которому введены обновленные критерии оценки эффективности работы глав субъектов федерации. В перечне 20 показателей на первом месте - доверие к власти со стороны населения ${ }^{2}$.

В нашем понимании, доверие, оставаясь морально-этической категорией, теперь законодательно отнесено к реальным конституционным приоритетам. Одной из причин этого, несомненно, стал кризис доверия, который переживает современное общество и система отношений по оси «социум - власть».

События последних лет буквально привели к переоценке казавшихся ранее незыблемыми аксиологических феноменов, перевернули многие истины. Финансовый кризис 2008 г. заметно снизил доверие к банкам и финансовым

\footnotetext{
1 Конституция Российской Федерации. Гл. 3. Ст. 75.1. Доступ: http://www.constitution. ru/10003000/10003000-5.htm (проверено 03.01.2021).

2 Указ Президента РФ от 04.02.2021 № 68 «Об оценке эффективности деятельности высших должностных лиц (руководителей высших исполнительных органов государственной власти) субъектов Российской Федерации и деятельности органов исполнительной власти субъектов Российской Федерации». - Президент России. Официальный сайт. Доступ: http:// kremlin.ru/acts/news/64970 (проверено 04.02.2021).
} 
институтам, считавшимися оплотом порядочности и стабильности, а также доверие бизнес-сообщества к правительствам и рейтинговым агентствам. Громкие разоблачения WikiLeaks в 2010 г. растоптали доверие к американской правящей элите, нанесли имиджевый урон всей западной демократии.

Пенсионная реформа 2018 г. сказалась на уровне доверия граждан к государственной власти в России. Ну а 2020 г., принесший пандемию COVID-19, стал просто рекордсменом по недоверию всех всему: достаточно прочитать новостные заголовки, чтобы узнать о недоверии бизнесменов к правительству, врачей - к вакцинам, Америки - к Китаю, граждан США - к Д. Трампу, родителей - к дистанционному образованию детей, россиян - к данным статистики. Интересно выстроил иерархию доверия во время пандемии лауреат Нобелевской премии по физике 2010 г. К. Новоселов: «Люди доверяют больше всего себе, близким, чуть-чуть государству и совсем не доверяют другим государствам» [Шеварнадзе 2020: 65].

Заметим, что в кризисных ситуациях модераторами процессов снижения доверия к власти выступают социально активные группы населения, точнее, те из них, интересы которых наиболее агрегированы и артикулированы. Речь идет в первую очередь о бизнесе.

Можно утверждать, что ощутимый ущерб доверию бизнеса к власти, к примеру, нанесла неопределенность действий последней в первые недели пандемии. Тем актуальнее оказалась высказывание М. Мишустина в выступлении в Государственной думе Федерального собрания РФ в момент одобрения на пост премьер-министра о необходимости вернуть утраченное доверие между бизнесом и властью ${ }^{1}$.

Разработка методов повышения доверия бизнеса и власти как значимого фактора социально-политического и экономического развития актуально в условиях становления цифровой экономики. Базовые принципы взаимоотношений вышеназванных институтов общества остаются неизменными. Про них нельзя забывать, увлекаясь технической стороной цифровизации. Доверие и в новых условиях остается не просто атрибутом, но и фактором, условием взаимоотношений и взаимодействия, позволяющим максимизировать эффект при минимизации затрат, а также снижающим риски инструментом.

\section{Доверие: сущность и виды}

В широком понимании доверие - это готовность человека к сотрудничеству и кооперации с людьми, не являющимися членами его семьи [Algan, Cahuc 2013]. Участники научно-методического семинара аналитического управления Аппарата Совета Федерации в рамках подготовки заседания Научноэкспертного совета при Председателе СФ на тему «Доверие как критический фактор достижения стратегических целей социально-экономического и политического развития государства» идентифицировали данный феномен и как делегирование полномочий (с законодательной точки зрения), и как тип социального капитала, и даже как специфическую власть, определяющую характер взаимоотношений между структурами управления и обществом [Доверие как критический фактор... 2020: 5, 10]. В Организации экономического сотрудничества и развития (ОЭСР) определили доверие как веру человека в то, что другой человек или организация будут действовать в соответствии с его оптими-

\footnotetext{
1 Мишустин: Необходимо вернуть утраченное доверие между властью и бизнесом. 2020. - Российская газета. 16.01. Доступ: https://rg.ru/2020/01/16/mishustin-neobhodimo-vernututrachennoe-doverie-mezhdu-vlastiu-i-biznesom.html (проверено 03.01.2021).
} 
стическими ожиданиями ${ }^{1}$. Доверие - это надежда людей, что те, от кого они зависят, оправдают их ожидания, сформулировал Роберт Шо [Шо 2000: 43].

Как видно из приведенных определений, доверие может быть рассмотрено как в системе взаимоотношений «личность-личность», так и в контекстах «Личность-институт» и «институт-институт».

В свете взаимоотношений бизнеса и власти мы определим доверие как ожидание или уверенность предпринимателей и бизнес-структур в том, что власть через своих представителей будет действовать в соответствии с их позитивными ожиданиями, и готовность делегировать власти часть своих полномочий. Особо отметим, что доверие, в нашем понимании, - категория не статичная, а связанная с действиями, сопровождающими доверительные отношения сторон и носящими рисковый характер, а также длящаяся во времени (перерастающая в привычку или традицию).

В рамках взаимоотношений бизнеса и власти доверие выполняет ряд социально-политических функций, среди которых наиболее значимы организующая, интегрирующая, коммуникативная, управленческая, стабилизирующая, прогностическая, ориентирующая, синергетическая функции. Высокий уровень доверия в отношениях бизнеса и власти обеспечивает самоорганизацию общества, одновременно выступает двигателем экономического развития и эффективности государства, ведет к более четкому соблюдению неформальных «правил игры» и законодательства, поддерживает социальный и политический консенсус в обществе, мобилизует вовлеченность бизнеса в процессы государственного управления, обеспечивает основу для развития других отношений [Авдеева 2019: 85].

Традиционно выделяют доверие людей друг к другу (межличностное) и доверие к власти, к институтам (социальное) [Леонова 2015: 36]. Причем более высокий уровень межличностного доверия оказывает влияние и на уровень доверия социального, являясь необходимым условием социальной активности людей.

По основанию доверие может возникать на эмоциональном отношении (эмоциональное), взвешивании и расчете (рациональное), договоренностях и нормах (институциональное) [Леонова 2015: 37].

В своих работах М. Вебер классифицировал социальное действие по четырем категориям: целерациональное, ценностно-рациональное, традиционное и аффективное [Вебер 2016: 84]. Хотя классик социологии и не исследовал отдельно феномен доверия, каждую из категорий можно положить в основу отдельного его вида и рассмотреть в контексте взаимоотношений бизнеса и власти.

Аффективное доверие - основанное на эмоциях, спонтанно возникающее. Такое доверие наиболее хрупко, т.к. не содержит под собой рациональных оснований и может так же пропасть с изменением настроения. Этот вид наиболее характерен для межличностных взаимоотношений, но возможен и в системе отношений «личность-институт». Например, во взаимоотношениях бизнеса и власти на уровень доверия может влиять сложившийся в советский период и до сих пор не истребленный из сознания некоторых чиновников (либо сознательно ими эксплуатируемый) стереотип «антиобщественности» рыночных отношений, вызывая определенные эмоции. С положительным знаком на доверие может воздействовать эмоциональный фон, идущий от масштабных событий, позитивно преподносимых общественности.

Традиционное доверие, т.е. сложившееся в силу привычки, исторически в

${ }^{1}$ Guidelines on Measuring Trust. 2020. - OECD.org. URL: https://www.oecd.org/governance/ oecd-guidelines-on-measuring-trust-9789264278219-en.htm (accessed 03.01.2021). 
России между государством (властью), бизнесом и обществом, характеризуется чрезвычайно низким уровнем. Британский историк Дж. Хоскинг назвал СССР 1920-30-х гг. страной максимального недоверия [Хоскинг 2016: 19]. Мессианский и апокалиптический нарратив, исключающее полутона деление на черное и белое - все это определяло сущность советской верхушки постреволюционного периода и, по мнению ученого, порождало глубокое доверие и глубокое недоверие. Фактическое отсутствие в СССР института свободного предпринимательства позволяет говорить о доверии предпринимательского сообщества и власти лишь в позднесоветский и постсоветский периоды. Социально-государственный слом в России того периода разрушил механизмы, обеспечивающие доверие между экономическими субъектами, а также между ними и государственной властью. Притязания олигархического бизнеса на управление политикой государства конца девяностых, переделы собственности нулевых, экономические, политические и даже эпидемиологический кризисы 2008-2020 гг. лишь усугубили проблему доверия.

Целеориентированное доверие возникает при работе для достижения общих целей. При этом можно выстроить смысловую цепочку: потребности и общественно значимые проблемы - цели как социальный заказ граждан власти и бизнесу - воплощение - результат как полученные услуги, решения, условия жизнедеятельности - доверие как соотношение целей и результатов.

В нашем понимании, заинтересованность бизнеса в решении общественно значимых проблем во многом детерминируется не столько степенью и уровнем корпоративной социальной ответственности предпринимательства, сколько взаимозависимостью бизнес-целей и интересов с представлениями об общественном консенсусе.

Ценностно-ориентированное доверие - при разделении общих ценностей. Исследования показывают, что бизнес и власть зачастую ставят перед собой не просто разные цели, но идут к ним с опорой на разные ценности. Пока бизнес считает ключевыми условиями роста экономики такие условия, как повышение эффективности институтов государства, демонополизация экономики, предсказуемость и последовательность экономической политики, власть направляет усилия на бюджетные инвестиции и снижение инфляции [Гончарова, Сидоренко 2013: 114]. Фундаментальные ценности, на которые предлагает обратить внимание бизнес, попросту зашориваются чисто техническими мерами со стороны государства.

Переход к информационному (сетевому, цифровому) обществу с преобладанием горизонтальных социальных связей ознаменовался выявлением автором концепции укорененности М. Грановеттером сетевого доверия, имеющего ключевое значение в современных экономических, социальных и политических отношениях [Грановеттер 2014: 354-359].

При этом следует учитывать нарастающее переформатирование социальных отношений под влиянием цифровых технологий, влияющее и на характер доверия. Наряду с классическими межличностным и институциональным доверием, в отношениях (в т.ч. бизнеса и власти) появляется дополняющее их сетевое доверие. Возникая там, где есть единые цели, где в отношениях есть предсказуемость и определенность, доверие способствует стабильности и продолжительности экономических отношений. Одновременно оно способствует легитимации власти, обеспечивая тем самым политическую устойчивость общества.

\section{Доверие власти и бизнеса в России}

Специалисты глобальной исследовательской и консалтинговой компании Edelman Data \& Intelligence отмечают, что в большинстве стран менее половины 
населения традиционно доверяет политическим и социальным институтам, а менее трети - бизнесу, что вызвано растущими системными неравенством и несправедливостью, диспропорциями в компетентности и этичности ${ }^{1}$. При этом Россия расположилась внизу рейтинга по уровню доверия. А это означает, что те же инвестиции бизнес будет делать в экономику тех стран, чей рейтинг доверия выше.

По результатам глубинного интервью, проведенного А.Н. Шохиным и А.В. Проскуриным с 15 предпринимателями в рамках исследования институционального доверия, был выявлен ряд проблем, понижающих уровень доверия бизнеса к власти. Среди них - сложности с программами поддержки малого и среднего предпринимательства (начиная с трудностей ее получения и заканчивая гипертрофированным вниманием контролирующих органов), некомпетентность и неконтактность чиновников, сложности налогового администрирования [Шохин, Проскурин 2019: 71]. Отметим также и непоследовательность предпринимательской и налоговой политики: вопреки обещаниям не повышать налоги, за последние 3 года повышены социальные взносы, НДС, налог на имущество, отменен ЕНВД [Горлов 2019: 50]. Отдельные исследователи отмечают существенное снижение уровня доверия из-за ухудшения качества коммуникации, а именно понятности информации, транслируемой от органов власти [Стратегические коммуникации... 2019: 109].

Существуют и «обратные претензии» к бизнесу со стороны государственной власти. Так, представители последней заявляют, что для повышения уровня доверия необходимо, чтобы бизнес платил достойную заработную плату; обеспечивал переподготовку кадров; проявлял больше этичности в отношениях с работниками и официальными органами (это требование взаимно [Черной 2014: 62]); воздерживался от насилия и нечестной конкуренции [Балашов 2019: 96]; сам не провоцировал коррупцию и не участвовал в «серых» и «черных» схемах; общался по принципу диалога, участвовал в партнерских программах; больше интересовался жизнью общества и активней участвовал в ее развитии - был социально ответственным.

По образному замечанию Р. Эдельмана, сейчас бизнес и власть похожи на детей разного веса на несбалансированных качелях: власть, воспринимаемая как менее компетентная и менее этичная, не в состоянии обеспечить необходимый противовес бизнесу, который считается высокоэффективным, но слишком корыстным ${ }^{2}$. Поэтому и возникает недоверие во взаимоотношениях бизнеса и власти, а также населения (общества) по отношению к ним обоим. Изменить сложившееся положение возможно с переходом к широкому внедрению современных информационно-коммуникационных и цифровых технологий.

\section{Цифровые технологии как инструмент повышения доверия}

Возникший уже в нашем веке новый вид доверия - цифровое доверие - можно определить как уверенность пользователей в безопасности и надежности цифровых систем, процессов и технологий [Веселов 2020: 134]. Цифровое доверие, таким образом, превращается в механизм обеспечения стабильности и поддержки социально-экономического развития, становится ключевым фактором конкурентоспособности цифровой экономики. Вся современная циф-

1 Edelman Trust Barometer 2020. - Edelman.com. January 18. URL: https://www.edelman.com/sites/g/files/aatuss191/files/2020-01/2020\%20Edelman\%20Trust\%20Barometer\%20 Global\%20Report.pdf (accessed 02.05.2021).

2 Edelman R. 2020. The Evolution of Trust. - Edelman.com. January 18. URL: https://www. edelman.com/research/evolution-trust (accessed 03.01.2021). 
ровая коммуникация принципиально основана на прозрачности событийной информации и доверии.

Можно предположить, что, укрепляя доверие к цифровой среде, поддерживая темпы инновационного развития, власть обеспечивает и обратный эффект - укрепляет доверие к самой власти. Ценности цифрового общества (равенство, справедливость, прозрачность, конфиденциальность, безопасность), реализующие доверие, едины для бизнеса, властных структур и институтов гражданского общества.

На новых платформах (экосистемах) взаимодействия бизнеса и власти применяются новые модели коммуникаций сторон, внедряются новые процессы, основанные на использовании современных технологий: блокчейна, больших данных, искусственного интеллекта и других цифровых технологий.

Технология блокчейна (распределенный регистр) просто создана для того, чтобы обеспечивать доверие в среде с изначально недоверенными узлами. Специалисты Банка Англии дали блокчейну определение, отталкиваясь именно от категории доверия: технология, позволяющая незнакомым людям совместно доверенно использовать запись событий [Генкин, Михеев 2018 : $64]$.

Технология позволяет обмениваться данными, платежами, услугами, товарами без посредников, дополнительного подтверждения, необходимости проверки третьими лицами и с высоким уровнем доверия, обеспеченным надежными криптографическими протоколами (шифрованием), неизменностью информации об авторе операции и невозможностью незаметной подделки или отмены операций задним числом. Сейчас только идет поиск сфер применения технологии во взаимоотношениях власти, бизнеса и общества. Несомненно, блокчейн позволит создать новый тип координации социальных и политических действий, новые виды экономической деятельности.

Не стоит, конечно, находится в плену иллюзии, что блокчейн способен решить все проблемы с доверием. Он довольно дорог в плане привязки к майнингу, делающему применение технологий массовым и тем самым обеспечивающим искомое доверие (да и финансово-правовой статус криптовалют во многих странах до конца не определен). Он ведет к деинституционализации взаимодействий, что содержит в себе риск возникновения нестабильности и дисбаланса в обществе, но не избавляет ни бизнес, ни власть от потребности в устанавливающих и контролирующих институтах.

Перспективы разумного и уместного применения технологии в системах взаимоотношений бизнеса и власти, вовлечение бизнеса в принятие политических решений и контроль их процедурной справедливости, повышающие взаимное доверие двух общественных институтов, несомненно, значительные. При этом важно отметить, что это доверие базируется не на силе, власти или морали, а защищено общественным консенсусом, носящим благодаря применению технологии практически аподиктический характер.

Технологии, связанные с большими данными, также могут взять на себя часть функций по установлению доверительных отношений. Доказано, что уровень доверия напрямую зависит от полноты и степени адекватности данных о партнерах взаимоотношений [Чупров, Зубок, Романович 2019: 149]. Незаметно собираясь и накапливаясь в реальном времени, большие данные (как официальные отчеты и данные, так и цифровые следы компаний и их контрагентов) можно использовать для построения репутационных рейтингов. Причем именно большие данные обеспечивают объективность оценок - сфальсифицировать гигантские объемы информации практически невозможно.

Активное развитие цифровых технологий позволяет рассмотреть еще одну 
(техническую) сторону исследуемой нами проблемы, а именно вопросы количественного измерения уровня доверия, сами подходы и методики его измерения, что до последнего времени было развито недостаточно. Не существовала ранее и техническая возможность отследить все многообразие проявлений доверия в социальных взаимоотношениях.

Сейчас традиционным источником больших данных являются, например, социальные сети в Internet, но последние, являясь социальными цифровыми платформами, имеют намного больший потенциал, чем просто агрегатор цифровых следов. Социальные сети, с одной стороны, обеспечивают рост доверия (новости мы получаем от простых, зачастую знакомых людей, которым доверяем), с другой - вносят лепту в формирование откровенных мифов и фейковых новостей, погружая общество в реальность (правильнее сказать, в «нереальность») постправды, становясь инструментом манипулирования массовым сознанием и снижая общий уровень доверия в социуме.

Можно однозначно отметить положительную тенденцию создания в социальных сетях страниц глав муниципалитетов и регионов, различных властных и контролирующих структур, что значительно приблизило власть к населению и бизнесу. Появилась возможность, если не совсем напрямую, то точно по укороченной траектории, обратиться к представителям власти с вопросами, проблемами и предложениями. Современные технологии позволяют сделать это оперативно, без затрат и разными удобными способами.

«Узким местом» использования социальных сетей и других негосударственных цифровых платформ в целях выстраивания взаимоотношений бизнеса и власти является отсутствие эффективных инструментов их регулирования и невозможность контроля действий их владельцев, что таит в себе серьезный риск потери каналов коммуникаций, утраты контроля над ситуацией и дестабилизации в экономике и политике в случаях проблем технического характера или целенаправленного враждебного вмешательства. Решить эту проблему можно только путем принятия национального и согласования международного законодательства, развития собственной цифровой отрасли и инфраструктуры.

При этом обезличенное общение бизнеса и власти посредством цифровых платформ, исключающее прямое общение там, где это только возможно, и позволяющее перевести процедуры в независимый режим принятия решений по заранее определенным алгоритмам, обеспечивает дополнительную защиту от коррупционных действий как со стороны представителей власти (вымогательство), так и со стороны предпринимательского сообщества (коммерческий подкуп).

Такое общение может выстраиваться при помощи технологии искусственного интеллекта. Конечно, использование искусственного интеллекта во взаимоотношениях бизнеса и власти должно быть четко стандартизировано, подчинено требованиям безопасности, надежности, сбалансированности прозрачности и конфиденциальности, согласовано с вопросами общественной морали, ценностей и этики. Подчеркнем, что внедрение цифровых технологий в государственное управление и систему взаимоотношений бизнеса, общества и власти возможно исключительно при условии формирования доверия к социальнополитическим институтам государства.

Таким образом, успешные практики использования для взаимоотношений бизнеса и власти официальных государственных платформ и неофициальных каналов, предоставляемых социальными сетями, в совокупности с цифровыми технологиями можно рассматривать как инструменты укрепления доверия между бизнес-структурами и государственными институтами. 


\section{Управление доверием в цифровой экономике}

По мнению Э. Гидденса, только активное доверие, которое завоевывается сторонами, позволяет построить устойчивые социальные отношения [Гидденс 1999: 295]. Для повышения доверия бизнеса и власти в условиях формирования цифровой экономики необходима реализация ряда мер как со стороны государства, так и со стороны бизнеса. Как сказал первый вице-премьер правительства РФ А. Белоусов в интервью в преддверии форума «Сильные идеи для нового времени», доверие - это не столько состояние, сколько действие, которое рождается только как совместное ${ }^{1}$. Добавим, что требуемые для преодоления недоверия усилия не могут носить разовый или временный характер - они должны быть постоянными.

В перечень мер, которые советуют принять государству в первую очередь, уже привычно помещают ряд пунктов, в которые мы внесли соответствующие реалиям цифровой трансформации экономики и социума дополнения.

Во-первых, власти необходимо обеспечить проведение активной и результативной социально-экономической политики, включающей эффективную инвестиционную политику, базирующуюся на обеспечении равноправности возможностей, выгод и рисков участников, гарантии верховенства закона и защищенности права собственности, корректировку действующей институциональной хозяйственной системы.

Обществу давно необходима новая экономическая модель, отвечающая реалиям цифровой эпохи. Не случайно страны ЕС свое дальнейшее развитие связывают с принципами устойчивого развития $E S G$ (экология, социальная ответственность, управление).

Во-вторых, власти необходимо создать условия для обеспечения потенциальной и реальной инклюзии представителей предпринимательского сообщества в процессы подготовки, принятия и реализации политических решений на различных уровнях. Одновременно необходимо установить границы допустимой степени вмешательства власти в деятельность субъектов предпринимательства в рамках приемлемого общественного консенсуса.

Основой процесса формирования и укрепления взаимного доверия бизнеса и власти должны стать обеспечиваемые цифровыми технологиями обратная связь, прозрачность и ясность в их отношениях, возможность, точнее, неотвратимость взаимного контроля. В данном контексте интересно предложение канадского политолога Н. Срничека о создании «общественных платформ», принадлежащих «простым» людям, не зависящих ни от надзорного аппарата государства, ни от бизнес-корпораций и обеспечивающих «чистоту» отношений сторон [Срничек 2020: 113].

Реальным движением в направлении укрепления доверия бизнеса к власти может стать создание экосистемы цифровой экономики, заявленное в национальной программе «Цифровая экономика Российской Федерации». Создание экосистемы среди прочего нацелено, во-первых, на обеспечение эффективного взаимодействия граждан, бизнеса и государства, во-вторых,

\footnotetext{
1 Белоусов: это десятилетие заставит Россию и мир в корне изменить модель развития. 2020. - Кто есть кто в Сибири. 11.11. Доступ: https://kto-irkutsk.ru/news/20201111/andrejbelousov-eto-desyatiletie-zastavit-rossiyu-i-mir-v-korne-izmenit-model-razvitiya (проверено 03.01.2021).
} 
на снятие существующих и противодействие появлению новых преград для развития высокотехнологичных бизнесов ${ }^{1}$.

Создание в 2020 г. центров управления регионом (ЦУР) можно признать шагом к оптимизации процессов агрегации общественных настроений и повышению оперативности реакции на изменения вектора и приоритетов доверительных отношений.

В-третьих, власти необходимо осуществить изменение государственной информационной политики с упором на качественное изменение политики просветительской (образовательной). Это должно обеспечить не только сдержанность и взвешенность в обещаниях, касающихся задач и прогнозов на краткосрочную и среднесрочную перспективы, но и отказ от манипуляторных средств воздействия на доверие, позволяющих достигать тактических побед, но не приносящих стратегических достижений, таких как создание менталитета осажденной крепости, суггестивная пропаганда, дезинформация, маленькие победоносные войны [Доверие как критический фактор... 2020: 26].

Необходимо развитие и обеспечение широкого доступа к современным цифровым технологиям, информации и данным, имеющим высокий прогностический потенциал.

Как мы отмечали ранее, формирование доверия - совместная работа для власти и бизнеса. Предприниматели не должны проявлять инертность во взаимоотношениях с государством, занимать позиции просителей и ведомых, а инициировать свои варианты улучшения ситуации. По нашему мнению, бизнес должен взять на себя более активную роль в возвращении доверия в общество, потому что он имеет наибольшую свободу действий и понятные цели, естественное стремление к постоянному обновлению. Причем, рассматривая отношения бизнеса и власти, нельзя не коснуться и третьей стороны - общества, представленного в этих отношениях как напрямую - работниками-населением, так и через различные представительские структуры в виде НКО, ассоциаций, иных социальных сетевых объединений. Система предлагаемых бизнесу мер, направленных на формирование доверительных отношений с властью, должна включать вопросы взаимодействия с гражданским обществом.

Во-первых, отечественному бизнесу необходимо преодолеть деформации экономического поведения и вернуться к исполнению характерных ему воспроизводственных задач, в т.ч. задач по внедрению инновационных цифровых технологий в производство. Решить проблему возможно, естественно, только при условии соответствующих действий власти по изменению институциональной среды.

Во-вторых, бизнесу необходимо отвечать на социальные ожидания общества и власти в форме этичного поведения, соблюдения законодательства, в т.ч. налогового. При этом бизнес должен быть уверен, что налоговое бремя будет справедливым, а расходование собранных средств - прозрачным; первостепенной задачей надзорных органов станет предупреждение нарушений, а не дополнительные сборы. Без реализации этих, на наш взгляд, очевидных положений невозможны и встречные шаги бизнеса.

В-третьих, бизнесу необходимо заниматься реализацией социальных проектов, в т.ч. направленных на нивелирование социально-политических вызовов и рисков цифровой трансформации экономики. При этом следует учесть результаты социологических исследований, которые показывают самоподдер-

1 Национальная программа «Цифровая экономика Российской Федерации». Утв. протоколом заседания президиума Совета при Президенте РФ по стратегическому развитию и национальным проектам от 04.06.2019 № 7. Доступ: https://digital.gov.ru/ru/activity/ directions/858/ (проверено 06.01.2021). 
живающийся характер сложившегося в обществе уровня недоверия [Мамаев 2019: 33]. Социально ответственные компании, занимающиеся благотворительной деятельностью, проявляющие заботу о работниках, соблюдающие этические нормы, увы, не получают сегодня от граждан-потребителей общественного одобрения и вынуждены тратить дополнительные ресурсы на $P R$ и рекламу социальных проектов. В конечном итоге, это значительно тормозит развитие социальной ответственности бизнеса.

Для формирования доверия с властью необходимо выстроить доверие с собственными работниками. А это вопрос снятия угрозы потери части или всего заработка - превращения основной массы работников в прекариат или безработных как воплощение худшего из рисков цифровизации экономики. Своевременно предупредить этот риск возможно, организовав систему обучения и переподготовки кадров. Инициатором в этом должен выступить бизнес, сам понимающий потребности реального сектора, а партнерство государства будет также играть положительную роль в формировании взаимного доверия в обществе.

Все предложенные меры и государству, и бизнесу, и обществу реально осуществить с опорой на современные цифровые технологии. Бизнес понимает жизненную необходимость цифровизации, в конце концов, не понимающие этого компании не выстоят в конкурентной борьбе. А вот чтобы управление доверием не превратилось в некую абстракцию для власти, необходима реальная цифровизация и самоцифровизация ее органов, суть которой не столько в переводе государственных и муниципальных услуг в цифровой формат, сколько в создании институтов, замене неэффективных управленческих процессов и коммуникационных сервисов новыми управленческими практиками, в своевременной разработке правовых процедур и норм цифрового общества. Технологии должны перестать быть лишь «дизайнерским украшением» официальных сайтов, а стать индикаторами и механизмами решения социальноэкономических и политических проблем.

\section{Заключение}

Подводя итоги, отметим, что доверие, несомненно, является одним из значимых факторов обеспечения социально-политической и экономической устойчивости общества, механизмом самоорганизации социума, оптимизации экономических отношений и легитимации власти. Цифровая трансформация, непосредственным образом затрагивая весь спектр взаимоотношений бизнеса, власти и общества, оказывает комплексное влияние на феномен доверия число связей стремительно растет, но их характер становится более слабым, хрупким и кратковременным.

Современные цифровые технологии несут в себе социально-политические и экономические риски, снижающие уровень доверия в отношениях, но и становятся инструментами формирования нового доверия. Растет радиус доверия, возникают новые его виды - сетевое, цифровое, преобразуются традиционные формы - например, институциональное доверие приобретает новые измерения в условиях возникновения и развития институтов электронной демократии. Рост уровня взаимного доверия бизнеса и власти способно инициировать в обществе проактивную позицию, вывести экономику из состояния стагнации, создать предпосылки для дальнейшей цифровой трансформации общества.

Эффективное социально-экономическое развитие невозможно без овладения властью всех уровней механизмами формирования доверительных отношений с бизнес-сообществом и общественными структурами на основе дол- 
госрочных соглашений [Ильичева, Лапин 2021: 189-190]. Многие вопросы, связанные с использованием цифровых технологий, требуют глубокой проработки, изменения институциональных норм хозяйствования, формулирования новых правил взаимоотношений и согласования трансформирующихся ценностей в изменившейся информационно-коммуникационной среде.

По нашему мнению, для успешного формирования доверия в новых условиях нарождающейся цифровой экономики и выполнения предложенных в данной работе мер необходимо заключить новый общественный договор между государством, бизнесом и обществом, закрепляющий приоритет партнерских отношений сторон, определяющий взаимные обязательства и ставящий общие цели для достижения.

\footnotetext{
Исследование выполнено при поддержке РФФИ в рамках научного проекта № 20-011-31357 «Технологии управления доверием к власти, упреждения угроз и вызовов региональной социально-политической стабильности».
}

\section{Список литературы}

Авдеева Д.А. 2019. Доверие в России и его связь с уровнем экономического развития. -Общественные науки и современность. № 3. С. 79-93.

Балашов А.М. 2019. Социальная ответственность предпринимательства как фактор обеспечения устойчивого экономического развития в современных условиях. - Карельский научный журнал. № 2(27). Т. 8. С. 96-98.

Вебер М. 2016. Хозяйство и общество: очерки понимающей социологии. В 4 т. Т. 1. Социология. М.: ИД ВШЭ. 445 с.

Веселов Ю.В. 2020. Доверие в цифровом обществе. - Вестник СанктПетербургского университета. Социология. Т. 13. Вып. 2. С. 129-143.

Генкин А., Михеев А. 2018. Блокчейн: Как это работает и что нас ждет завтра. М.: Альпина Паблишер. 592 с.

Гидденс Э. 1999. Социология. М.: Эдиториал УРСС. 703 с.

Гончарова О.Ю. Сидоренко И.Н. 2013. Взаимное доверие государства и бизнеса - основа решения задач экономического развития России. Государственное и мунищипальное управление. Ученые записки СКАГС. № 2. С. 112-124.

Горлов К.Н. 2019. Возможные социально-политические и экономические последствия изменений в налогообложении коммерческого имущества (на материалах Тамбовской области). - Известия Тульского государственного университета: гуманитарные науки. Вып. 4. С. 49-58.

Грановеттер М. 2014. Экономическое действие и социальная структура: проблема укорененности. - Классика новой экономической социологии. М.: ИД ВШЭ. С. 345-379.

Доверие как критический фактор достижения стратегических иелей социально-экономического и политического развития государства. Аналитический вестник № 5(748) (под общ. ред. В.Д. Кривова). 2020. М.: Совет Федерации Федерального Собрания РФ. 58 с.

Ильичева Л.Е., Лапин А.В. 2021. Стратегии социально-экономического развития регионов в ракурсе национальных целей и приоритетов: Политический анализ: монография. М.: Аспект Пресс. 272 с.

Леонова И.Ю. 2015. Доверие: понятие, виды и функции. - Вестник Удмуртского университета. Философия. Психология. Педагогика. Т. 25. Вып. 2. C. 34-41.

Мамаев А.И. 2019. Проблемы развития социальной ответственности малого и среднего бизнеса. - Дискуссия. Вып. 95. С. 30-36. 
Срничек Н. 2020. Капитализм платформ. М.: ИД ВШЭ. 128 с.

Стратегические коммуникации в цифровую эпоху (под ред. Л.С. Сальниковой). 2019. М.: Научная библиотека. 300 с.

Хоскинг Дж. 2016. Доверие: история. М.: Политическая энциклопедия. 296 с.

Черной Л.С. 2014. Предпринимательская этика и экономическое развитие: парадоксы современности. - Экономическая наука современной России. № 4(67). С. 49-64.

Чупров В.И., Зубок Ю.А., Романович Н.А. 2019. Доверие в саморегуляции изменяющейся социальной реальности. М.: Норма. $208 \mathrm{c}$.

Шеварнадзе С.П. 2020. Будущее сегодня: как пандемия изменила мир. М.: Эксмо. 224 с.

Шо Р.Б. 2000. Ключи к доверию в организации: Результативность, порядочность, проявление заботы. М.: Дело. 272 с.

Шохин А.Н., Проскурин А.В. 2019. Факторы взаимного доверия института бизнеса и института власти в современной России. - Бизнес. Общество. Власть. № 2. C. 64-73.

Algan Y., Cahuc P. 2013. Trust, Growth, and Well-Being: New Evidence and Policy Implications. - Discussion Paper. N 7464. URL: http://repec.iza.org/dp7464.pdf (accessed 02.05.2021).

GORLOV Konstantin Nikolaevich, applicant of the Institute of Socio-Political Studies, Russian Academy of Sciences; Senior Lecturer of the Chair of Management and Business Administration, Michurinsk State Agrarian University; Deputy Chairman of the Michurinsk City Council of Deputies of the Tambov Region (973 Krasnaya St, Michurinsk, Tambov Region, Russia, 393764; gorlov@cit-tmb.ru)

PEN'KOV Vladimir Fedorovich, Dr.Sci. (Pol.Sci.), Professor of the Chair of Theory and History of State and Law, Tambov State Technical University; Chairman of the Public Chamber of the Tambov Region (106 Sovetskaya St, Tambov, Russia,392000;pvf68@mail.ru)

\section{GENERATING CONFIDENCE BETWEEN BUSINESS AND GOVERNMENT IN CONDITIONS OF DIGITALIZATION OF THE RUSSIAN ECONOMY}

\footnotetext{
Abstract. The article examines the modern understanding of the essence and types of trust in the context of the relationship between business and government. The authors analyze the influence of digitalization of economy and sociopolitical processes on the level of trust in the Russian Federation. It has been determined that modern digital technologies (blockchain, artificial intelligence, big data, digital platforms) become both sources of socio-political and economic risks that reduce the level of trust in relationships, and tools for creating new trust in the system of relationships between business and government. The authors propose a number of measures that are necessary for implementation by both the authorities and the business in order to build effective mechanisms for the formation of mutual trusting relationships. They especially note a need to conclude a new social contract that meets the realities of the digital transformation of society.

Keywords: trust, digital trust, business, government, digital economy, digital technologies, social contract
} 